\title{
Cryogenic preservation of fish and mammalian spermatozoa
}

\author{
M. S. Mounib \\ Department of Fisheries \& the Environment, Fisheries and Marine Service, Technology Branch, \\ P.O. Box 429, Halifax, Nova Scotia B3J 2R3, Canada
}

\begin{abstract}
Summary. Various combinations of sucrose, reduced glutathione and potassium bicarbonate were tested for the cryogenic preservation of salmon spermatozoa. When a fast freezing procedure was followed, the extender that gave the best results was composed of 1 part of dimethyl sulphoxide (DMSO), as a protective agent, and 7 parts of a medium containing $125 \mathrm{~mm}$-sucrose, $6.50 \mathrm{~mm}$-reduced glutathione and $100 \mathrm{~mm}$-potassium bicarbonate. Salmon and cod spermatozoa were kept frozen in this extender for 1 year. Freezing resulted in a reduction in the number of motile spermatozoa but had no significant effect on the degree of progression of motile spermatozoa or on their fertilizing capacity. When glycerol replaced DMSO in the extender and a slow freezing procedure was followed, similar results were obtained for the spermatozoa of bull or man; although the number of motile spermatozoa was reduced, there was no effect on the progressive motility score.
\end{abstract}

\section{Introduction}

Previous work from this laboratory (Mounib, Hwang \& Idler, 1968) has shown that spermatozoa of cod, Gadus morhua, when suspended in a medium composed of 40 parts of $0.4 \mathrm{M}-\mathrm{NaCl}-0 \cdot 1$ M-glycine, 8 parts $1.3 \%$ sodium bicarbonate and 10 parts glycerol can be stored frozen at a temperature of -79 or $-196^{\circ} \mathrm{C}$ and retain their fertilizing capacity. The same medium has been used successfully for freezing the spermatozoa of other marine fish, e.g. plaice, Pleuronectes platessa (Pullin, 1972), haddock, Melanogrammus aeglefinus, and Atlantic herring, Clupea harengus harengus (M. S. Mounib, unpublished). However, attempts to use the same extender for freezing spermatozoa from fish that normally spawn in fresh water, such as Atlantic salmon, Salmo salar, have not been successful (Truscott \& Idler, 1969). Hoyle \& Idler (1968) used a modified Cortland medium containing $2.5 \%$ lactose and $5 \%$ ethylene glycol to freeze Atlantic salmon spermatozoa for $30 \mathrm{~min}$ and obtained a maximum fertilizing capacity of $12 \%$. Fertilities of $5-19 \%$ were later obtained with salmon spermatozoa frozen in an extender of a chemical composition based on that of the seminal plasma of fish (Truscott \& Idler, 1969). However, neither the ovarian fluid (Graybill, 1968) nor the seminal plasma (Ott, 1970) were suitable as extending media for the spermatozoa of spring chinook salmon, Oncorhynchus ishawtscha. Graybill \& Horton (1969) achieved up to $18 \%$ fertilization from steelhead trout (Salmo gairdneri) spermatozoa that had been cryo-preserved in a modified Cortland medium containing fructose, lecithin and dimethyl sulphoxide (DMSO). Further work (Ott \& Horton, 1971a) showed that chinook salmon spermatozoa, frozen in a modified Cortland medium containing lecithin, fertilized an average of $23.4 \%$ of eggs whereas fresh spermatozoa had a fertilization rate of $98 \%$. Experiments with coho salmon (Oncorhynchus kisutch) spermatozoa frozen in the presence of mannitol and DMSO gave $35 \%$ fertilized eggs compared with $58 \%$ for control spermatozoa (Ott \& Horton, 1971a). These authors also found that there was no apparent effect of dilution of the spermatozoa with this extender, dilution ratios of $1: 4$ to $1: 19$ giving an average of $71 \%$ fertilized eggs from spermatozoa that had been frozen; however, fertility results with control fresh spermatozoa were not included. A $59 \%$ fertilization rate was reported (Ott \& Horton, 1971b) for steelhead trout ova inseminated with frozen-thawed spermatozoa, compared with $97 \%$ for those inseminated with fresh spermatozoa, when sodium bicarbonate, lecithin and mannitol at 750,750 and $250 \mathrm{mg} / 100 \mathrm{ml}$ respectively were included in the extender with the most effective concentration of DMSO $(12 \%)$. 
In all the above-mentioned experiments, with the exception of those of Pullin (1972), frozenthawed spermatozoa fertilized fewer ova than did fresh spermatozoa. In the present study we investigated the development of a new sperm freezing method so that the spermatozoa of Atlantic salmon could be frozen and retain their fertilizing capacity. Because the early results were encouraging, the procedure was tested for the spermatozoa of a marine fish species, and preliminary investigations were carried out with spermatozoa of bull and man.

\section{Materials and Methods}

Ripe male fish (25 Atlantic salmon, Salmo salar, and $10 \mathrm{cod}$, Gadıs morhua) were used. They were kept in tanks supplied with running fresh or sea water, as required, and three collections of semen were made from each male. The average volume of semen per collection was $15 \mathrm{ml}$ and was sufficient for preparation of a minimum of 100 ampoules. Semen from 10 Holstein bulls (3-5 years old) and 10 healthy men (22-25 years old) was also tested. The average volume per ejaculate was $6 \mathrm{ml}$ from bulls and $3.52 \mathrm{ml}$ from men and was enough to give 40 and 25 ampoules, respectively. The average sperm counts per $\mathrm{ml}$ semen were $1.22 \times 10^{7}, 1.31 \times 10^{7}, 1.0 \times 10^{6}$ and $1.19 \times 10^{5}$ for salmon, cod, bull and man respectively.

\section{Suspending medium}

The medium contained sucrose, reduced glutathione and potassium bicarbonate, and different concentrations of these chemicals were tried. Dimethyl sulphoxide (DMSO) and glycerol were the protective agents used for fish and mammalian spermatozoa respectively. In all cases the extender was prepared by mixing 1 part of the protective agent (DMSO or glycerol) with 7 parts of the medium.

\section{Semen collection}

Semen was collected as previously described (Mounib et al., 1968) and mixed with 3 parts of the extender containing the protective agent. Penicillin $(5000 \mathrm{i} . \mathrm{u} . / \mathrm{ml})$ was added and $0.5 \mathrm{ml}$ of the sperm suspension was pipetted into 2-ml ampoules placed over crushed ice. The ampoules were then sealed and immediately frozen.

\section{Freezing of spermatozoa}

Because preliminary work indicated that slow freezing of salmon spermatozoa did not give satisfactory results, all our attempts were based on fast freezing procedures (Tables 1, 2 and 3) and two methods were tried. (1) A two-step freezing method in which the sealed ampoules were immersed in a slush of acetone-solid $\mathrm{CO}_{2}\left(-79^{\circ} \mathrm{C}\right)$ and left for $1 \mathrm{~h}$ before removal for storage in liquid nitrogen $\left(-196^{\circ} \mathrm{C}\right)$. (2) A one-step freezing method in which the sealed ampoules were plunged directly into liquid nitrogen $\left(-196^{\circ} \mathrm{C}\right)$. Mammalian spermatozoa were frozen slowly, at a rate of $1{ }^{\circ} \mathrm{C} / \mathrm{min}$, by adding cold acetone until the temperature reached $-25^{\circ} \mathrm{C}$ (Mounib et al., 1968); the ampoules were then plunged into liquid nitrogen.

Frozen spermatozoa were thawed by putting the ampoules in a $38^{\circ} \mathrm{C}$ water bath until the semen had liquefied, and then into an ice bath. The ampoules were opened and spermatozoa were tested for motility and fertility.

\section{Sperm assessment}

Motility. This was assessed in two ways. (1) The number of motile spermatozoa was expressed as a percentage of the total number of spermatozoa, and (2) the degree of progression of the motile spermatozoa was calculated on a scale of $0-10$ in which 1 referred to a very feeble spermatozoon and 10 referred to a spermatozoon with good progressive motility. The scoring in these two categories, 
particularly for fish spermatozoa, was arbitrary since fish spermatozoa are motile under the microscope for a short period only (Mann, 1964).

Fertilizing capacity. This was determined by mixing fresh spermatozoa or frozen-thawed spermatozoa with eggs from the same female fish. The incubation procedure was similar to that described by Truscott, Idler, Hoyle \& Freeman (1968). In every test, a minimum of 500 eggs was incubated and the percentage of fertilization was determined.

\section{Statistical analysis}

Tests of motility scores of spermatozoa and percentages of fertilized eggs were carried out in triplicate and duplicate respectively, and the averages were obtained. The differences between the

Table 1. The effect of different concentrations of sucrose and reduced glutathione in the extender on motility scores (mean \pm s.e.m. for 15 tests) and fertilizing capacity (mean \pm s.e.m. for 5 tests) of fresh and frozen spermatozoa of Atlantic salmon

\begin{tabular}{|c|c|c|c|c|c|c|c|}
\hline \multirow{3}{*}{$\begin{array}{c}\text { Sucrose } \\
\text { conc. } \\
\text { (mM) }\end{array}$} & \multirow{3}{*}{$\begin{array}{l}\text { Glutathione } \\
\text { conc. } \\
\text { (mm) }\end{array}$} & \multicolumn{3}{|c|}{ Fresh spermatozoa } & \multicolumn{3}{|c|}{ Frozen spermatozoa $\dagger$} \\
\hline & & \multicolumn{2}{|c|}{ Motility scores } & \multirow{2}{*}{$\begin{array}{c}\% \\
\text { Fertilized } \\
\text { eggs }\end{array}$} & \multicolumn{2}{|c|}{ Motility scores } & \multirow{2}{*}{$\begin{array}{c}\% \\
\text { Fertilized } \\
\text { eggs }\end{array}$} \\
\hline & & $\begin{array}{l}\% \text { Motile } \\
\text { sperm. }\end{array}$ & Progression & & $\begin{array}{l}\% \text { Motile } \\
\text { sperm. }\end{array}$ & Progression & \\
\hline Control & Control & $91 \cdot 4 \pm 4 \cdot 1$ & $7 \cdot 2 \pm 0.40$ & $83 \cdot 6 \pm 4 \cdot 7$ & $0^{*}$ & $0^{*}$ & $0^{*}$ \\
\hline 250 & 0 & $92 \cdot 0 \pm 3 \cdot 2$ & $7.3 \pm 0.29$ & $80 \cdot 0 \pm 4 \cdot 2$ & $7 \cdot 1 \pm 0.6^{*}$ & $2 \cdot 0 \pm 0.19 *$ & $6 \cdot 2 \pm 1 \cdot 0^{*}$ \\
\hline 250 & $3 \cdot 25$ & $91.2 \pm 2.9$ & $7 \cdot 0 \pm 0.36$ & $84 \cdot 4 \pm 3 \cdot 9$ & $12 \cdot 3 \pm 0 \cdot 9^{*}$ & $3.0 \pm 0.15^{*}$ & $16.9 \pm 1.9 *$ \\
\hline 250 & $6 \cdot 50$ & $91.4 \pm 3.7$ & $7.4 \pm 0.35$ & $89 \cdot 0 \pm 4 \cdot 0$ & $21 \cdot 4 \pm 1 \cdot 1^{*}$ & $5 \cdot 1 \pm 0 \cdot 20^{*}$ & $49 \cdot 4 \pm 3.0^{\circ}$ \\
\hline 250 & $9 \cdot 75$ & $90 \cdot 2 \pm 4 \cdot 0$ & $7 \cdot 2 \pm 0.27$ & $86 \cdot 7 \pm 2 \cdot 8$ & $20 \cdot 3 \pm 1 \cdot 7^{*}$ & $5 \cdot 0 \pm 0.21^{*}$ & $48 \cdot 1 \pm 3 \cdot 7^{*}$ \\
\hline 125 & 0 & $93 \cdot 0 \pm 3 \cdot 3$ & $7 \cdot 1 \pm 0.45$ & $85 \cdot 3 \pm 3 \cdot 7$ & $9 \cdot 4 \pm 0.7^{*}$ & $2.6 \pm 0.13^{*}$ & $15 \cdot 3 \pm 3 \cdot 0^{*}$ \\
\hline 125 & $3 \cdot 25$ & $91 \cdot 3 \pm 4 \cdot 1$ & $7 \cdot 3 \pm 0.31$ & $81 \cdot 9 \pm 5 \cdot 0$ & $22 \cdot 0 \pm 1 \cdot 1^{*}$ & $5 \cdot 3 \pm 0.20^{*}$ & $53.4 \pm 2.6$ \\
\hline 125 & $6 \cdot 50$ & $92 \cdot 0 \pm 3 \cdot 0$ & $7 \cdot 4 \pm 0 \cdot 30$ & $86 \cdot 4 \pm 4 \cdot 2$ & $33 \cdot 1 \pm 1 \cdot 3^{*}$ & $7 \cdot 1 \pm 0 \cdot 29$ & $85 \cdot 2 \pm 4.0$ \\
\hline 125 & $9 \cdot 75$ & $92.4 \pm 3.9$ & $7 \cdot 2 \pm 0 \cdot 32$ & $85 \cdot 2 \pm 5 \cdot 3$ & $30 \cdot 2 \pm 2 \cdot 0^{*}$ & $6.4 \pm 0.30$ & $71.1 \pm 4.9$ \\
\hline
\end{tabular}

The extender used was composed of 1 part of DMSO : 7 parts of a medium that contained 100 mm-potassium bicarbonate and sucrose and reduced glutathione at the concentrations indicated. One part of semen was mixed with 3 parts of extender. In control treatments, no extender was used.

* These values were significantly different $(P<0.001)$ from the corresponding values for fresh spermatozoa.

$\dagger$ A fast two-step freezing method was applied and spermatozoa were stored frozen for 2 weeks.

Table 2. The effect of different concentrations of potassium bicarbonate in the extender on motility scores (mean \pm s.e.m. for 15 tests) and fertilizing capacity (mean \pm s.e.m. for 5 tests) of fresh and frozen salmon spermatozoa

\begin{tabular}{|c|c|c|c|c|c|c|c|}
\hline \multirow{3}{*}{$\begin{array}{c}\text { Bicarbonate } \\
\text { conc. } \\
\text { (mM) }\end{array}$} & \multirow[b]{3}{*}{$\mathrm{pH}$} & \multicolumn{3}{|c|}{ Fresh spermatozoa } & \multicolumn{3}{|c|}{ Frozen spermatozoa $\uparrow$} \\
\hline & & Motilit & scores & & Motili & scores & \\
\hline & & $\begin{array}{l}\% \text { Motile } \\
\text { sperm. }\end{array}$ & Progression & $\begin{array}{l}\text { Fertilized } \\
\text { eggs }\end{array}$ & $\begin{array}{l}\% \text { Motile } \\
\text { sperm. }\end{array}$ & Progression & $\begin{array}{c}\text { Fertilized } \\
\text { eggs }\end{array}$ \\
\hline 0 & $3 \cdot 6$ & $90 \cdot 3 \pm 4 \cdot 2$ & $7 \cdot 2 \pm 0.32$ & $84 \cdot 0 \pm 3 \cdot 9$ & $3 \cdot 0 \pm 0.4$ & $2 \cdot 0 \pm 0.21^{*}$ & $5 \cdot 0 \pm 0.3^{*}$ \\
\hline 50 & $7 \cdot 42$ & $92 \cdot 0 \pm 5 \cdot 1$ & $7 \cdot 3 \pm 0 \cdot 41$ & $85 \cdot 2 \pm 4 \cdot 1$ & $14 \cdot 3 \pm 1 \cdot 0^{*}$ & $4 \cdot 3 \pm 0 \cdot 19^{*}$ & $11 \cdot 0 \pm 0.9^{*}$ \\
\hline 75 & $7 \cdot 45$ & $91 \cdot 4 \pm 2.9$ & $7 \cdot 1 \pm 0.32$ & $81.9 \pm 3.5$ & $21 \cdot 4 \pm 1 \cdot 2^{*}$ & $5.9 \pm 0.30^{*}$ & $44 \cdot 6 \pm 2 \cdot 2^{*}$ \\
\hline 100 & $7 \cdot 57$ & $93 \cdot 2 \pm 4 \cdot 7$ & $7.4 \pm 0.29$ & $84 \cdot 6 \pm 2 \cdot 8$ & $34 \cdot 2 \pm 2 \cdot 5^{*}$ & $7.0 \pm 0.20$ & $82.9 \pm 4.0$ \\
\hline 125 & $7 \cdot 73$ & $90 \cdot 2 \pm 3 \cdot 8$ & $7 \cdot 4 \pm 0.25$ & $80.9 \pm 2.9$ & $32 \cdot 0 \pm 2 \cdot 7^{*}$ & $6.8 \pm 0.34$ & $75 \cdot 0 \pm 3 \cdot 2$ \\
\hline 150 & $7 \cdot 77$ & $91 \cdot 1 \pm 5 \cdot 0$ & $7 \cdot 2 \pm 0.20$ & $82 \cdot 8 \pm 4 \cdot 0$ & $29 \cdot 1 \pm 1.9^{*}$ & $5 \cdot 0 \pm 0.26^{*}$ & $23 \cdot 0 \pm 2 \cdot 0^{*}$ \\
\hline
\end{tabular}

The extender used was composed of 1 part of DMSO: 7 parts of a medium that contained 125 mM-sucrose, 6.5 mM-reduced glutathione and potassium bicarbonate at the concentration indicated. One part of semen was mixed with 3 parts of the extender.

* These values were significantly different $(P<0.001)$ from the corresponding values for fresh spermatozoa.

$\dagger$ A fast two-step freezing method was applied. Spermatozoa were stored frozen for 2 weeks. 
motility scores and percentages of eggs fertilized by the fresh and frozen spermatozoa were examined by Student's $t$ test (Snedecor, 1956).

\section{Results}

\section{Fish spermatozoa}

The effects of different concentrations of sucrose, reduced glutathione and potassium bicarbonate are shown in Tables 1 and 2. Frozen salmon spermatozoa that had no extender were rendered immotile and lost their fertilizing capacity, whereas all the extenders provided some degree of protection. The medium that contained $125 \mathrm{~mm}$-sucrose, $6.50 \mathrm{~mm}$-reduced glutathione and $100 \mathrm{~mm}$ potassium bicarbonate offered the best protection of motility and fertilizing capacity. The number of motile spermatozoa in this extender after freezing was about one-third the value for fresh spermatozoa but the degree of progression of the motile spermatozoa and their fertilizing capacity was almost the same (Tables 1 and 2). The differences in the degree of progression of motile spermatozoa and in the percentage of fertilized eggs may be specifically due to the bicarbonate concentrations used or to the resulting $\mathrm{pH}$ changes of the media (Table 2). Experiments involving the replacement of bicarbonate by a phosphate or a Tris buffer ( $\mathrm{pH} 7.57)$ resulted in a reduction in the motility scores of salmon spermatozoa and their fertilizing capacity after freezing (M. S. Mounib, unpublished) and suggest the importance of using potassium bicarbonate in the cryopreservation medium for salmon spermatozoa.

Fast freezing of Atlantic salmon spermatozoa by plunging the sealed ampoules directly into liquid nitrogen gave results similar to those from the two-step fast-freezing procedure, as judged by the degree of progression of motile spermatozoa and fertilizing capacity 12 months later (Table 3 ). The

Table 3. Effect of freezing on motility scores (mean \pm s.e.m. for 10 tests) and fertilizing capacity (mean \pm s.e.m. for 5 tests) of salmon and cod spermatozoa

\begin{tabular}{|c|c|c|c|c|c|c|}
\hline \multirow[b]{3}{*}{ Fish } & \multicolumn{3}{|c|}{ Fresh spermatozoa } & \multicolumn{3}{|c|}{ Frozen spermatozoa $\dagger$} \\
\hline & \multicolumn{2}{|c|}{ Motility scores } & \multirow[b]{2}{*}{$\begin{array}{c}\% \text { Fertilized } \\
\text { eggs }\end{array}$} & \multicolumn{2}{|c|}{ Motility scores } & \multirow[b]{2}{*}{$\begin{array}{c}\% \text { Fertilized } \\
\text { eggs }\end{array}$} \\
\hline & $\begin{array}{l}\% \text { Motile } \\
\text { sperm. }\end{array}$ & Progression & & $\begin{array}{l}\% \text { Motile } \\
\text { sperm. }\end{array}$ & Progression & \\
\hline Salmon & $93 \cdot 1 \pm 6 \cdot 1$ & $7 \cdot 5 \pm 0.21$ & $82 \cdot 7 \pm 5 \cdot 6$ & $33.4 \pm 2 \cdot 1^{*}$ & $6.9 \pm 0.29$ & $80 \cdot 0 \pm 4.9$ \\
\hline $\operatorname{Cod}$ & $90 \cdot 4 \pm 4 \cdot 7$ & $7 \cdot 6 \pm 0 \cdot 32$ & $63 \cdot 0 \pm 4 \cdot 2$ & $35 \cdot 2 \pm 1 \cdot 7^{*}$ & $7 \cdot 1 \pm 0.26$ & $59 \cdot 3 \pm 3 \cdot 8$ \\
\hline
\end{tabular}

The extender was composed of 1 part of DMSO:7 parts of a medium containing $125 \mathrm{~mm}$-sucrose, $6.5 \mathrm{~mm}$-reduced glutathione and $100 \mathrm{~mm}$-potassium bicarbonate. One part of semen was mixed with 3 parts of the extender.

* These values were significantly different $(P<0.001)$ from the corresponding value for fresh spermatozoa.

Table 4. Effect of freezing on motility scores (mean \pm s.e.m. for 10 tests) of human and bull spermatozoa

\begin{tabular}{|c|c|c|c|c|}
\hline & \multicolumn{2}{|c|}{ Fresh spermatozoa } & \multicolumn{2}{|c|}{ Frozen spermatozoa $\dagger$} \\
\hline & \multicolumn{2}{|c|}{ Motility score } & \multicolumn{2}{|c|}{ Motility score } \\
\hline & $\%$ Motile sperm. & Progression & $\%$ Motile sperm. & Progression \\
\hline Man & $62 \cdot 9 \pm 1 \cdot 7$ & $7 \cdot 6 \pm 0.42$ & $25 \cdot 6 \pm 2 \cdot 6^{*}$ & $6.4 \pm 0.44$ \\
\hline Bull & $80 \cdot 1 \pm 2 \cdot 0$ & $8.2 \pm 0.37$ & $40.4 \pm 1.9^{*}$ & $7.6 \pm 0.23$ \\
\hline
\end{tabular}

The extender consisted of 1 part of glycerol: 7 parts of a medium containing 125 mm-sucrose, $6.5 \mathrm{~mm}$-reduced glutathione and $100 \mathrm{~mm}$-potassium bicarbonate. One part semen was mixed with 3 parts of extender.

* These values were significantly different $(P<0.001)$ from the corresponding value for fresh spermatozoa.

$\dagger$ Slow freezing (see text). Spermatozoa were stored frozen for 1 month. 
one-step fast-freezing method gave comparable results for fresh and frozen ( 13 months) cod spermatozoa (Table 3). Although the spermatozoa that survived the freezing procedure possessed good motility and retained their fertilizing capacity, there was a reduced number of motile spermatozoa for both species. Some of the fertilized salmon and cod eggs were kept in incubation tanks until hatching and the salmon and cod larvae derived from frozen spermatozoa were similar to those from fresh spermatozoa. Freezing of spermatozoa did not affect the incubation period from fertilization to hatching of the eggs or the percentage of eggs hatching.

\section{Mammalian spermatozoa}

When the one- or two-step fast-freezing methods were applied to the spermatozoa of bull or man, the fall in the percentage of motile spermatozoa after freezing was substantial (data not shown). Slow freezing $\left(1^{\circ} \mathrm{C} / \mathrm{min}\right)$ resulted in a reduction of the percentage of motile spermatozoa for both species but the degree of progression of motile spermatozoa was only slightly reduced (Table 4).

\section{Discussion}

The ability of spermatozoa to fix carbon dioxide, first shown for fish spermatozoa (Mounib, 1967; Mounib \& Eisan, 1967, 1968), has also been demonstrated for ram (O'Shea \& Wales, 1967) and bull (Sexton \& Flipse, 1971) spermatozoa. In addition, Mounib \& Eisan (1968) and Mounib (1974) found that spermatozoa possess at least four carbon dioxide-fixing enzymes, i.e. propionyl CoA carboxylase, phosphoenolpyruvate carboxykinase, and NAD- and NADP-malic enzymes, and that all these enzymes are stable when stored frozen in a medium that contained $0.25 \mathrm{M}$-sucrose, reduced glutathione $(0 \cdot 1 \%, w / v), \operatorname{EDTA}(0.1 \%, w / v)$ and Tris $(0.05 \mathrm{M})$. This observation suggested that a modification of such a medium might be a suitable extender for spermatozoa to be frozen, and in the present study two modifications were introduced: (1) bicarbonate was substituted for Tris because it was satisfactory in the extender developed for freezing cod spermatozoa (Mounib et al., 1968), and (2) EDTA was excluded because of its chelating effect. The present results show that the sucrose-reduced glutathione-potassium bicarbonate medium can preserve the progressive motility and fertilizability of fish spermatozoa stored frozen. The results with mammalian spermatozoa frozen in this extender need to be substantiated by determining the fertilizing capacity of the frozen-thawed spermatozoa. We lack the facilities for carrying out such work, but invite other workers to do so.

\section{References}

Graybill, J.R. (1968) Cryo-preservation of viable fish sperm. M.Sc. Thesis, Oregon State University, Corvallis.

Graybill, J.R. \& Horton, H.F. (1969) Limited fertilization of steelhead trout eggs with cryo-preserved sperm. J. Fish. Res. Bd Can. 26, 1400-1404.

Hoyle, R.J. \& IDLER, D.R. (1968) Preliminary results in the fertilization of eggs with frozen sperm of Atlantic salmon (Salmo salar). J. Fish. Res. Bd Can. 25, 12951297.

Mann, T. (1964) The Biochemistry of Semen and of the Male Reproductive Tract, 2 nd edn. Methuen, London.

MoUNIB, M.S. (1967) Metabolism of pyruvate, acetate and glyoxylate by fish sperm. Comp. Biochem. Physiol. 20, 987-992.

MoUNiB, M.S. (1974) NAD- and NADP-malic enzymes in spermatozoa of mammals and fish. FEBS Letters 48, 79-84.

MoUnib, M.S. \& EISAN, J.S. (1967) Fixation of carbon dioxide by cod sperm. Fedn Proc. Fedn Am. Socs exp. Biol. 26, 645 .
Mounib, M.S. \& EISAN, J.S. (1968) Carbon dioxide fixation by spermatozoa of cod. Comp. Biochem. Physiol. 25, 703-709.

Mounib, M.S., Hwang, P.C. \& IDleR, D.R. (1968) Cryogenic preservation of Atlantic cod (Gadus morhua) sperm. J. Fish. Res. Bd Can. 25, 2623-2632.

O'SheA, T. \& WAles, R.G. (1967) Fixation of carbon dioxide by ram spermatozoa.J. Reprod. Fert. 14, 333334.

OTr, A.G. (1970) Fertilization of salmonid eggs with cryopreserved sperm. M.Sc. Thesis, Oregon State University, Corvallis.

OtT, A.G. \& Horton, H.F. (1971a) Fertilization of chinook and coho salmon eggs with cryo-preserved sperm. J. Fish. Res. Bd Can. 28, 745-748.

OtT, A.G. \& Horton, H.F. (1971b) Fertilization of steelhead trout (Salmo gairdneri) eggs with cryopreserved sperm.J. Fish. Res. Bd Can. 28, 1915-1918.

Pullin, R.S.V. (1972) The storage of plaice (Pleuronectes platessa) sperm at low temperatures. Aquaculture 1, 279-283. 
Sexton, T.J. \& Flipse, R.J. (1971) Carbon dioxide fixation by bovine semen, washed spermatozoa, and seminal plasma. J. Dairy Sci. 54, 417-419.

SNedecor, G.W. (1956) Statistical Methods, 5th edn. Iowa State College Press, Ames, Iowa.
Truscort, B. \& IDLER, D.R. (1969) An improved extender for freezing Atlantic salmon spermatozoa. J. Fish. Res. Bd Can. 26, 3254-3258.

Truscott, B., IDler, D.R., Hoyle, R.J. \& Freeman, H.C. (1968) Sub-zero preservation of Atlantic salmon sperm. J. Fish. Res. Bd Can. 25, 363-372.

Received 8 June 1977 